\title{
Comparison of 0.9-mm and 1.4-mm catheters in excimer laser coronary angioplasty for acute myocardial infarction
}

\author{
Sho Nagamine ${ }^{1,2}$ (1) Takashi Ashikaga $^{2,3} \cdot$ Shinichiro Masuda ${ }^{1} \cdot$ Kota Komiyama $^{4} \cdot$ Takaaki Tsuchiyama $^{1,2}$. \\ Takashi Shibui ${ }^{1,2} \cdot K_{\text {Kenzo Hirao }}^{2}$
}

Received: 30 December 2018 / Accepted: 6 March 2019 / Published online: 16 March 2019

(C) The Author(s) 2019

\begin{abstract}
Excimer laser coronary angioplasty (ELCA) is a unique revascularization modality that can vaporize plaque and thrombus. Compared to thrombus aspiration therapy, ELCA is reported to provide better microcirculation and reduced peripheral embolism in treatment for acute coronary syndrome. Excimer laser catheters come in various sizes, and we sought to compare the 0.9 - and 1.4-mm-diameter catheters. We retrospectively enrolled 90 acute myocardial infarction (AMI) patients who underwent primary percutaneous coronary intervention with excimer laser from August 2013 to March 2017 in our hospital. Patients were grouped by diameter of catheter that had been used, the $0.9 \mathrm{~mm}$ group $(n=51)$ and $1.4 \mathrm{~mm}$ group $(n=39)$. We evaluated myocardial perfusion, procedural success rate, short-term outcome, lesion crossability, and complications between the two groups. The percentage of patients whose final thrombolysis in myocardial infarction (TIMI) grade was $3(0.9 \mathrm{~mm} 86.3 \%$ vs $1.4 \mathrm{~mm}$ $89.7 \% p=0.75)$ and final myocardial blush grade (MBG) was $3(0.9 \mathrm{~mm} 72.5 \%$ vs $1.4 \mathrm{~mm} 69.2 \% p=0.82)$ was similarly high for both groups. Procedural success rate, in-hospital major adverse cardiac events (MACE), lesion crossability, and complications were also similar. This study showed that efficacy of 0.9 and $1.4 \mathrm{~mm}$ excimer laser catheter was equivalent in ELCA for AMI patients. If one takes into account lesion crossability, debulking effects, and the stunned platelets phenomenon, the $0.9 \mathrm{~mm}$ excimer laser catheter is sufficient for ELCA in AMI patients.
\end{abstract}

Keywords Percutaneous coronary intervention $\cdot$ ELCA $\cdot$ Myocardial blush grade $\cdot$ TIMI grade $\cdot 0.9 \mathrm{~mm} \cdot 1.4 \mathrm{~mm}$

\section{Introduction}

Excimer laser coronary angioplasty (ELCA) is a unique revascularization modality that recently became available in Japan. Sometimes referred to as photoablation, ELCA uses ultraviolet light to vaporize or debulk atherosclerotic plaque and thrombus $[1,2]$. ELCA has been shown to be

Sho Nagamine

nagasho13@yahoo.co.jp

1 Department of Cardiology, Tokyo Metropolitan Hiroo Hospital, 2-34-10, Ebisu, Shibuya-ku, Tokyo 153-0013, Japan

2 Department of Cardiovascular Medichine, Tokyo Medical and Dental Hospital, Tokyo, Japan

3 Department of Cardiology, Musashino Red Cross Hospital, Tokyo, Japan

4 Department of Cardiology, Mitsui Memorial Hospital, Tokyo, Japan feasible and safe for the treatment of patients with acute myocardial infarction (AMI) [3-6].

Despite many advances in reperfusion therapy for coronary artery disease, problems remain. The no reflow phenomenon is one of them that occur in a notable proportion of patients with AMI. No reflow is associated with reduced left ventricular ejection fraction, left ventricular remodeling, and poor clinical outcomes, indicating that merely re-establishing patency in a blocked artery is not good enough [7,8]. The CARMEL multicenter trial found that ELCA was an effective and safe revascularization modality for treatment of AMI [9].

Furthermore, ELCA provided better microcirculation and was better able to cross lesions in ACS patients compared to thrombus aspiration therapy [10]. Excimer laser catheters come in $0.9,1.4,1.7$, and $2.0 \mathrm{~mm}$ diameters. It is currently unknown if there is an optimal catheter size for treatment with ELCA for AMI. The current study compares the efficacy and safety of 0.9 and $1.4 \mathrm{~mm}$ catheters in ELCA used in treatment of AMI patients. 


\section{Methods}

\section{Study population}

We retrospectively analyzed consecutive AMI patients who underwent percutaneous coronary intervention (PCI) with ELCA at Tokyo Metropolitan Hiroo Hospital, from August 2013 to March 2017. The AMI was diagnosed on the basis of AHA/ACC criteria [11, 12]. The present study was performed with approval of the hospital ethics committee. All of the patients provided written informed consent to receive ELCA treatment and have their data used. Major criteria for exclusion were onset to device time $\geqq 24 \mathrm{~h}$ and cardiopulmonary arrest on hospital arrival. We also excluded patients who underwent extracorporeal membrane oxygenation, intravenous injection of tissue plasminogen activator, and intracoronary injection of thrombolytic agents or in whom both 0.9 and $1.4 \mathrm{~mm}$ excimer laser catheters were used. At our hospital, 1.7 and $2.0 \mathrm{~mm}$ catheters are rarely used because these catheters require a greater than $7 \mathrm{Fr}$ guide catheter. There were only two instances of use of those catheters during our study period, so we excluded these sizes from consideration. The indication for ELCA was decided by the operator based on imaging studies, namely, angiography and intravascular ultrasound (IVUS) or optical coherence tomography (OCT) results. During the same period, 50 AMI patients underwent classical PCI (i.e., PCI without ELCA), and there were no significant differences in patient characteristics between the excimer laser and classical PCI groups. The operator was inclined to select classical PCI for smaller vessels.

\section{Catheter procedure}

All patients were pretreated with aspirin and clopidogrel or prasugrel before PCI. Loading dose was aspirin $200 \mathrm{mg}$, clopidogrel $300 \mathrm{mg}$, and prasugrel $20 \mathrm{mg}$ respectively. Anticoagulation during PCI was achieved with intravenous unfractionated heparin boluses given to maintain an activated clotting time $\geqq 300 \mathrm{~s}$. All ELCA procedures were conducted using the Spectranetics CVX-300 platform (Spectranetics, Colorado, CO, USA), consisting of an excimer laser generator (CVX 300) and pulsed xenon-chlorine laser catheters capable of delivering Excimer energy (wavelength $308 \mathrm{~nm}$, pulse length $185 \mathrm{~ns}$ ) from 30 to $80 \mathrm{~mJ} / \mathrm{mm}^{2}$ (fluence) at pulse repetition rates of 25 to $80 \mathrm{~Hz}$. The operator decided whether patients were treated with concentric 0.9- or 1.4-mm excimer laser catheters based on the angiographic and intracoronary imaging studies. We tended to use the smaller 0.9-mm excimer laser catheter for and arteries which had a bend proximal to the lesion and the $1.4 \mathrm{~mm}$ otherwise. The fluence and repetition rate were determined by the operator, but $90 \%$ of the patients were started with fluence of $45 \mathrm{~mJ} / \mathrm{mm}^{2}$ and repetition rate of $25 \mathrm{~Hz}$, which are the initial settings recommended by the company. The guiding catheter was filled with saline before lasing. The operator advanced the laser catheter at a speed of $0.5 \mathrm{~mm} / \mathrm{s}$ while an assistant injected saline at 2-3 ml/s [13]. After the first round, angiography and intracoronary imaging were repeated in order to determine whether to modify fluence and repetition rate on the next round. After ELCA, PCI was performed according to standard techniques. All but two patients underwent IVUS or OCT. Most patients underwent stent deployment with either a bare metal stent (BMS) or drug eluting stent (DES). We sometimes administered intracoronary injection of vasodilators such as nitroprusside, nicorandil, verapamil, and adenosine to improve slow flow and no reflow phenomenon. CAG and IVUS images from a representative patient with AMI who underwent ELCA are shown in Fig. 1. The coronary angiogram finding was improved by ELCA, and IVUS revealed a reduction of thrombus.

\section{Post-PCI management}

All patients were given $100 \mathrm{mg}$ aspirin daily and $75 \mathrm{mg}$ clopidogrel or $3.75 \mathrm{mg}$ prasugrel daily after PCI. Optimal medication such as $\beta$-blockers, angiotensin-converting enzyme inhibitors, angiotensin II receptor blockers, and statins was prescribed at the discretion of the attending doctors. Most patients received these medications.

\section{Study endpoints and definition}

We evaluated myocardial reperfusion according to thrombolysis in myocardial infarction (TIMI) grade and myocardial blush grade (MBG) $[14,15]$. The primary end point was achievement of TIMI grade 3 and MBG 3. Secondary end points were procedural success rate, in-hospital major adverse cardiac events (MACE), lesion crossability, and complications. Procedural success was defined as a reduction of lumen diameter stenosis to $<30 \%$ and final TIMI grade 3. In-hospital MACE was defined as cardiac death, myocardial infarction, stent thrombosis, and target lesion revascularization (TLR). TLR was defined as a repeat revascularization by either PCI or coronary artery bypass graft (CABG) while in hospital. Stent thrombosis was classified according to the Academic Research Consortium definition as definite, probable, or possible [16]. Lesion crossability was evaluated by whether the excimer laser catheter could be delivered to the lesion. Complications were evaluated by the incidence of perforation, dissection, slow flow or no reflow, and loss of side branches ( $\geqq 2.0 \mathrm{~mm}$ diameter) after both ELCA and PCI. Perforation was defined as the demonstration of contrast medium beyond the vessel wall. Major dissection was defined as type $\mathrm{C}$ or worse, and minor dissection was defined as type A or B according to the National Heart Lung and Blood Institute classification [17]. Slow flow or no-reflow was defined as inadequate myocardial perfusion through a given segment of coronary circulation without angiographic evidence of mechanical vessel obstruction [18]. 
Fig. 1 CAG and IVUS images from a representative patient with AMI who underwent ELCA
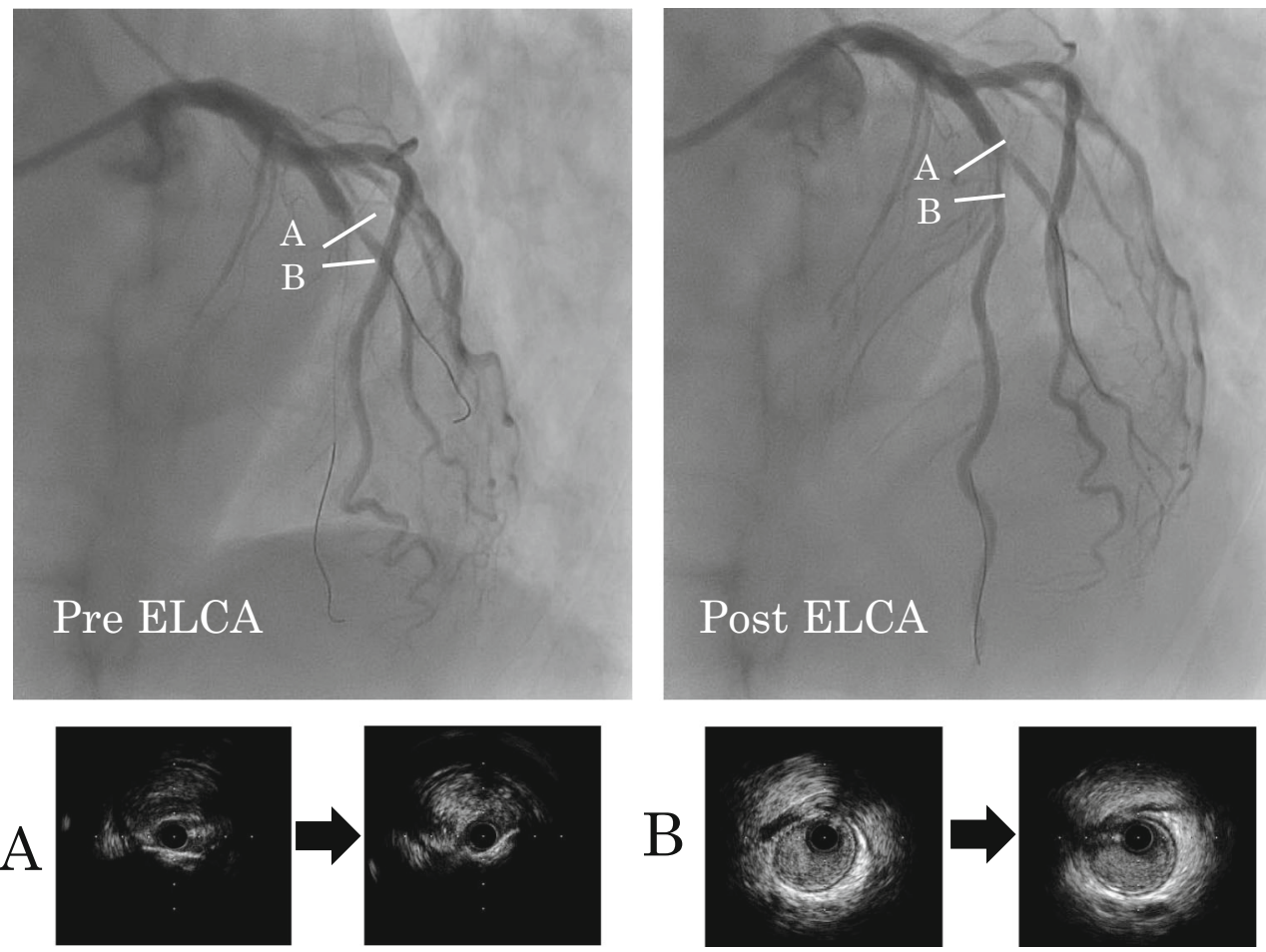

\section{Angiographic analysis}

Coronary angiograms were obtained for angiographic analysis and reviewed by three experienced observers. Angiographic TIMI grade and MBG were visually estimated as previously described. Quantitative coronary angiography (QCA) was performed by means of CAAS 5.9 (Pie Medical, Maastricht, the Netherlands.)

\section{Statistical analysis}

Categorical data are expressed as \% (n). Continuous data are expressed as mean $\pm \mathrm{SD}$. Categorical data were analyzed using Fisher's exact test or the chi-squared test. Between-group comparison of the continuous data was conducted using unpaired $t$ test, and skewed data were assessed using the Mann-Whitney $U$ test. All tests were two-sided, and a significance level of 0.05 was set. Statistical analysis was performed using SPSS version 23 (IBM SPSS Statistics, IBM, Armonk, NY, USA).

\section{Results}

\section{Baseline clinical, angiographic, and procedural characteristics}

There were 51 patients who had received ELCA with 0.9-mm excimer laser catheters and 39 who had received the 1.4-mm excimer laser catheter. The proportion of STEMI patients was approximately $82 \%$. Baseline clinical characteristic for the two groups are listed in Table 1. There were no significant differences between the two groups with regard to age, sex, and common coronary risk factors. The proportion of STEMI patients was similar between the two groups. Neither were there statistical differences in onset to device time, peak creatine kinase $(\mathrm{CK})$, and peak creatine kinase-myocardial band (CK-

Table 1 Patient characteristics

\begin{tabular}{llll}
\hline & $0.9 \mathrm{~mm}(n=51)$ & $1.4 \mathrm{~mm}(n=39)$ & $p$ value \\
\hline Diagnosis & & & 0.59 \\
STEMI & $43(84.3)$ & $31(79.5)$ & \\
$\quad$ NSTEMI & $8(15.7)$ & $8(20.5)$ & \\
Age (years) & $67.4 \pm 15.1$ & $66.1 \pm 13.8$ & 0.68 \\
Male & $43(84.3)$ & $29(74.4)$ & 0.29 \\
Hypertension & $25(49.0)$ & $21(53.8)$ & 0.68 \\
Diabetes mellitus & $16(31.4)$ & $13(33.3)$ & 1.0 \\
Dyslipidemia & $28(54.9)$ & $23(59.0)$ & 0.83 \\
Smoking & $32(62.7)$ & $21(53.8)$ & 0.52 \\
History of PCI & $7(13.7)$ & $7(17.9)$ & 0.77 \\
History of CABG & $2(3.9)$ & $0(0)$ & 0.50 \\
Killip class 1-2 & $43(84.3)$ & $31(79.5)$ & 0.59 \\
LVEF before PCI (\%) & $49.1 \pm 11.3$ & $53.4 \pm 13.4$ & 0.11 \\
Onset to device time (min) & $314.2 \pm 262.5$ & $394.2 \pm 296.0$ & 0.18 \\
Peak CK (IU/L) & $2581 \pm 2147$ & $2656 \pm 1975$ & 0.87 \\
Peak CK-MB (IU/L) & $224 \pm 181$ & $271 \pm 276$ & 0.34 \\
\hline
\end{tabular}

Data given as mean $\pm \mathrm{SD}$ or $n(\%)$

$C K$ creatine kinase, $C K-M B$ creatine kinase-myocardial band, $C A B G$ coronary artery bypass grafting, $L V E F$ left ventricular ejection fraction, NSTEMI non-ST-segment elevation myocardial infarction, STEMI STsegment elevation myocardial infarction, $P C I$ percutaneous coronary intervention 
MB). Angiographic characteristics are listed in Table 2. The distribution of culprit lesions differed significantly $(p=0.02)$. The proportion of left anterior descending (LAD) lesions was higher in the $0.9 \mathrm{~mm}$ group, and the proportion of left circumflex (LCX) lesions was higher in the $1.4 \mathrm{~mm}$ group. The initial TIMI grade and initial MBG were not significantly different between the two groups. Procedural characteristics are listed in Table 3. The use of thrombus aspiration, distal protection, vasodilator, and intraaortic balloon pumping was not significantly different between the two groups. However, maximum fluence and repetition were significantly higher for the 0.9 than $1.4 \mathrm{~mm}$ group with $p$ values of 0.04 and 0.03 respectively. The timing of ELCA (whether it was preceded by thrombus aspiration or balloon dilatation) was similar, and 50-60\% patients underwent ELCA directly. Evaporation time was similar.

\section{QCA results}

The baseline data of QCA are listed in Table 4. There were no significant differences between the two groups regarding baseline lesion length, reference vessel diameter, MLD (minimum lumen diameter), \%DS (diameter stenosis), and plaque burden. We evaluated the excimer laser efficacy by analyzing QCA after ELCA. The acute gain after ELCA was not significantly different between the two groups $(0.9 \mathrm{~mm} 0.23 \pm$ $0.44 \mathrm{~mm}$ vs $1.4 \mathrm{~mm} 0.26 \pm 0.41 \mathrm{~mm}, p=0.82)$. The amount of plaque reduction was also similar $\left(0.9 \mathrm{~mm} 11.8 \pm 20.6 \mathrm{~mm}^{3}\right.$ vs $\left.1.4 \mathrm{~mm} 13.9 \pm 21.7 \mathrm{~mm}^{3}, p=0.68\right)$. According to the QCA results, the improvement of angiographic findings after ELCA was not particularly large. There were no significant differences between the two groups.

\section{Procedural and angiographic results}

The distribution of lesion TIMI grades and MBG is shown for before and after PCI for the two groups in Fig. 2. Final TIMI grade and final MBG were not significantly different between the two groups. Procedural success rate, in-hospital MACE, lesion crossability, and complications between the two groups are listed in Table 5 and Fig. 3. Regarding these results, there were no significant differences between the two groups.

\section{Discussion}

This retrospective study compared the efficacy of 0.9 and $1.4 \mathrm{~mm}$ catheter sizes in patients who underwent PCI with ELCA. We found no significant differences in myocardial perfusion before and after ELCA between the two groups. Procedural success rate, in-hospital MACE, and complications were also similar. We conclude that the efficacy of the $0.9 \mathrm{~mm}$ and $1.4 \mathrm{~mm}$ excimer laser catheter is equivalent in AMI patients. Previous studies have shown the safety and efficacy of ELCA compared with manual thrombus aspiration. The Japanese ULTRAMAN registry showed that ELCA was effective and safe even for the thrombotic lesions [19]. However, previous studies have not evaluated the effects of excimer laser catheter size.
Table 2 Baseline angiographic characteristics

\begin{tabular}{|c|c|c|c|}
\hline & $0.9 \mathrm{~mm}(n=51)$ & $1.4 \mathrm{~mm}(n=39)$ & $p$ value \\
\hline Culprit lesion & & & 0.02 \\
\hline LAD & $32(62.7)$ & 17 (43.6) & \\
\hline LCX & $2(3.9)$ & $9(23.1)$ & \\
\hline RCA & $17(33.3)$ & $13(33.3)$ & \\
\hline LMT & $0(0)$ & $0(0)$ & \\
\hline Lesion type & & & 0.63 \\
\hline $\mathrm{A} / \mathrm{B} 1$ & $3(5.9)$ & $1(2.6)$ & \\
\hline $\mathrm{B} 2 / \mathrm{C}$ & $48(94.1)$ & $38(97.4)$ & \\
\hline Number of diseased vessels $(n)$ & $1.56 \pm 0.81$ & $1.49 \pm 0.72$ & 0.62 \\
\hline Baseline TIMI grade & & & 0.74 \\
\hline $0-1$ & $28(54.9)$ & $24(61.5)$ & \\
\hline 2 & $14(27.5)$ & $8(20.5)$ & \\
\hline 3 & $9(17.6)$ & $7(17.9)$ & \\
\hline Pre ELCA TIMI grade & & & 0.81 \\
\hline $0-1$ & $13(25.5)$ & $8(20.5)$ & \\
\hline 2 & $20(39.2)$ & $15(38.5)$ & \\
\hline 3 & $18(35.3)$ & $16(41.0)$ & \\
\hline Post-ELCA TIMI grade & & & 0.64 \\
\hline $0-1$ & 11 (21.6) & $6(15.4)$ & \\
\hline 2 & $12(23.5)$ & $12(30.8)$ & \\
\hline 3 & $28(54.9)$ & $21(54.4)$ & \\
\hline
\end{tabular}

Data given as mean $\pm \mathrm{SD}$ or $n(\%)$

$E L C A$ excimer laser coronary angioplasty, $M B G$ myocardial blush grade, $L A D$ left anterior descending, $L M T$ left main trunk, $L C X$ left circumflex, $R C A$ right coronary artery, TIMI thrombolysis in myocardial infarction 
Table 3 Procedural characteristics

\begin{tabular}{llll}
\hline & $0.9 \mathrm{~mm}(n=51)$ & $1.4 \mathrm{~mm}(n=39)$ & $p$ value \\
\hline Stent implantation & $48(94.1)$ & $31(79.5)$ & 0.05 \\
Stent size (mm) & $3.29 \pm 0.58$ & $3.32 \pm 0.45$ & 0.78 \\
Stent length (mm) & $34.2 \pm 15.0$ & $30.8 \pm 16.0$ & 0.34 \\
Direct stenting & $34(66.7)$ & $21(53.8)$ & 0.28 \\
Thrombus aspiration & $22(43.1)$ & $25(64.1)$ & 0.06 \\
Distal protection & $2(3.9)$ & $2(5.1)$ & 1.0 \\
Vasodilator & $21(41.2)$ & $17(43.6)$ & 0.83 \\
IABP & $6(11.8)$ & $6(15.4)$ & 0.76 \\
Maximum fluence (mJ/mm $\left.{ }^{2}\right)$ & $56.8 \pm 6.6$ & $53.9 \pm 6.3$ & 0.04 \\
Maximum repetition (Hz) & $36.9 \pm 6.6$ & $33.8 \pm 6.2$ & 0.03 \\
Evaporation time of excimer laser (s) & $395.5 \pm 229.2$ & $408.1 \pm 330.5$ & 0.84 \\
Timing of ELCA & & & 0.43 \\
Direct ELCA & $31(60.8)$ & $19(48.7)$ & \\
Post-thrombus aspiration & $18(35.3)$ & $19(48.7)$ & $1(2.6)$ \\
Post-balloon dilatation & $2(3.9)$ & & \\
\hline
\end{tabular}

Data given as mean $\pm \mathrm{SD}(\%)$

$I A B P$ intraaortic balloon pumping

A previous review for catheter selection suggests that size of the vessel and nature of the lesion be considered [20]. It is natural to select the largest possible diameter catheter that the diseased vessel will accommodate to debulk the maximum amount of plaque before the subsequent intervention such as angioplasty and stenting. The laser catheter diameter should not exceed two-thirds of the reference vessel diameter. However, narrower lumens and heavily calcified lesions may not accommodate larger diameter catheters. Smaller catheters have higher fluence and frequency ranges, because there is less risk of perforation. Conversely, larger catheters have lower ranges [21]. The most frequently used size cited in various Japanese studies is $1.7 \mathrm{~mm}$, whereas in the USA, the most frequently used size is $0.9 \mathrm{~mm}$
[22]. Our study is the first to compare clinical efficacy of different catheter sizes, albeit for the two smallest diameter catheters. We found no significant differences in efficacy between 0.9 - and 1.4$\mathrm{mm}$ catheters for AMI patients. We believe there are two main explanations for this result. Firstly, a narrower irradiation range from a smaller catheter can be compensated for by increasing fluence and repetition as suggested by the significantly higher maximum fluence and repetition recorded in this study for the $0.9-\mathrm{mm}$ catheter. In the last year of our study, the X-80 (Spectranetics, Colorado, CO, USA) catheter became available in Japan from May 2016. The X-80 had a maximum fluence of $80 \mathrm{~mJ} / \mathrm{mm}^{2}$ and repetition of $80 \mathrm{~Hz}$, which made it easier to achieve greater debulking with the smaller catheter. Secondly,

Table 4 QCA results

\begin{tabular}{llll}
\hline & $0.9 \mathrm{~mm}(n=51)$ & $1.4 \mathrm{~mm}(n=39)$ & $p$ value \\
\hline Baseline QCA data & & & \\
$\quad$ Lesion length (mm) & $22.4 \pm 12.3$ & $18.2 \pm 9.1$ & 0.09 \\
Reference diameter (mm) & $2.70 \pm 0.73$ & $2.56 \pm 0.64$ & 0.36 \\
MLD (mm) & $0.67 \pm 0.27$ & $0.63 \pm 0.37$ & 0.59 \\
$\% \mathrm{DS}(\%)$ & $74.2 \pm 10.7$ & $74.5 \pm 13.5$ & 0.92 \\
Plaque burden $\left(\mathrm{mm}^{3}\right)$ & $50.8 \pm 47.8$ & $41.8 \pm 27.5$ & 0.32 \\
Acute gain after ELCA $(\mathrm{mm})$ & $0.23 \pm 0.44$ & $0.26 \pm 0.41$ & 0.82 \\
Plaque reduction after ELCA $\left(\mathrm{mm}^{3}\right)$ & $11.8 \pm 20.6$ & $13.9 \pm 21.7$ & 0.68 \\
Final QCA data & & & 0.62 \\
MLD (mm) & $2.67 \pm 0.82$ & $2.59 \pm 0.78$ & 0.90 \\
\%DS $(\%)$ & $13.9 \pm 9.2$ & $14.3 \pm 17.2$ & 0.12 \\
Plaque burden $\left(\mathrm{mm}^{3}\right)$ & $13.5 \pm 15.7$ & $22.6 \pm 36.6$ & \\
\hline
\end{tabular}

Data given as mean $\pm \mathrm{SD}$ or $n(\%)$

$M L D$ minimum lumen diameter, $Q C A$ quantitative coronary angiographic analysis, $\% D S \%$ diameter stenosis 
Fig. 2 TIMI grade and MBG. This graph shows TIMI grade at pre and final angiogram. The proportion of final TIMI grade 3 was not significantly different between the two groups $(0.9 \mathrm{~mm}$ group $86.3 \%$ vs $1.4 \mathrm{~mm}$ group $89.7 \%, p=0.75)$. This graph shows MBG pre and final angiogram. The proportion of final MBG 3 was not significantly different between the two groups ( $0.9 \mathrm{~mm}$ group $72.5 \%$ vs $1.4 \mathrm{~mm}$ group $69.2 \%, p=0.82$ )
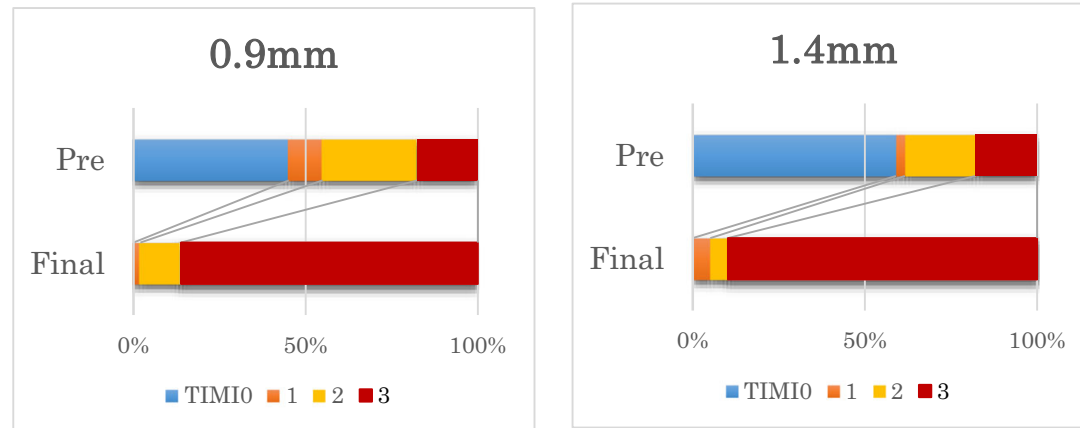

This graph shows TIMI grade at pre and final angiogram. The proportion of final TIMI grade3 was not significantly different between the two groups $(0.9 \mathrm{~mm}$ group $86.3 \%$ vs $1.4 \mathrm{~mm}$ group $89.7 \% \mathrm{p}=0.75)$.
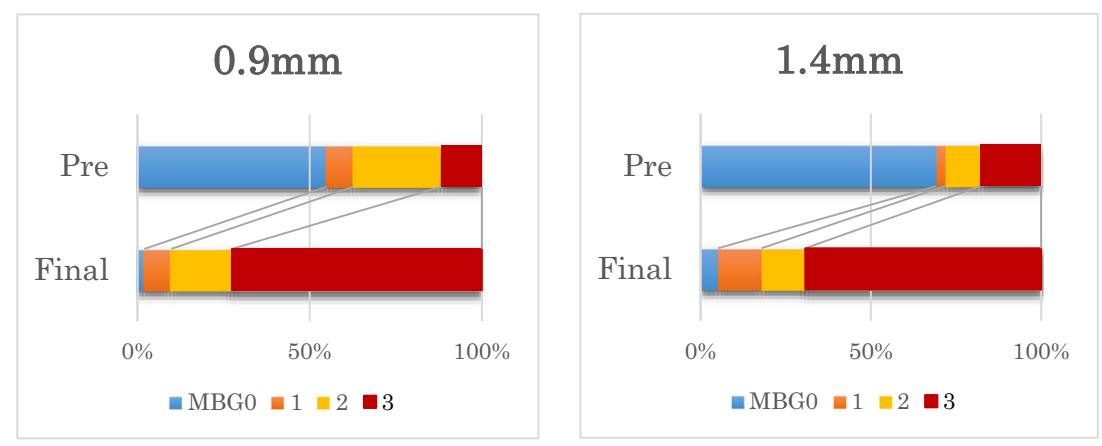

This graph shows MBG pre and final angiogram. The proportion of final MBG 3 was not significantly different between the two groups $(0.9 \mathrm{~mm}$ group $72.5 \%$ vs $1.4 \mathrm{~mm}$ group $69.2 \% \mathrm{p}=0.82$ ).

the excimer laser not only vaporizes thrombus and plaque but also dose dependently suppresses adenosine diphosphate aggregation. This latter effect is called the stunned platelets phenomenon $[23,24]$ and stabilizes thrombus in AMI culprit lesions, regardless of catheter size. Based on these ways that the excimer

Table 5 Procedural results

\begin{tabular}{llll}
\hline & $0.9 \mathrm{~mm}(n=51)$ & $1.4 \mathrm{~mm}(n=39)$ & $p$ value \\
\hline Procedural success & $43(84.3)$ & $34(87.2)$ & 0.77 \\
Lesion crossability & $50(98.0)$ & $35(89.7)$ & 0.16 \\
ELCA complications & $4(7.8)$ & $6(15.4)$ & 0.32 \\
Perforation & $0(0)$ & $0(0)$ & $\mathrm{n} . \mathrm{s}$ \\
Slow flow or no-reflow & $3(5.9)$ & $5(12.8)$ & 0.29 \\
Side branch occlusion & $0(0)$ & $0(0)$ & $\mathrm{n} . \mathrm{s}$ \\
Major dissection & $1(2.0)$ & $0(0.0)$ & 1.0 \\
Ulceration & $0(0)$ & $1(2.6)$ & 0.43 \\
Post-PCI complications & 0 & 0 & $\mathrm{n} . \mathrm{s}$ \\
\hline
\end{tabular}

Data given as $n(\%)$ laser achieves its effects, we believe the $0.9-\mathrm{mm}$ excimer laser catheters can bestow sufficient peripheral circulation despite its narrower range of evaporation. We believe the $0.9-\mathrm{mm}$ size excimer laser catheter is sufficient to obtain debulking effect and thrombus evaporation for AMI patients, while likely having advantages with respect to lesion crossing ability.

\section{Limitations}

Several limitations of this study should be acknowledged. First, this study was a single-center, non-randomized, retrospective analysis and the sample size was relatively small. Second, the size of excimer laser catheter was decided on by the operator after consideration of angiographic findings and imagings, i.e., catheter size choice was not randomized. However, analysis showed that diseased vessel characteristics including vessel diameter and lesion severity were similar for the two catheter groups. Another limitation is that the operator decided whether to perform ELCA or not. However, analysis we conducted in 
Fig. 3 In-hospital MACE. CABG coronary artery bypass grafting, MI myocardial infarction, MACE major adverse cardiac events, TLR target lesion revascularization

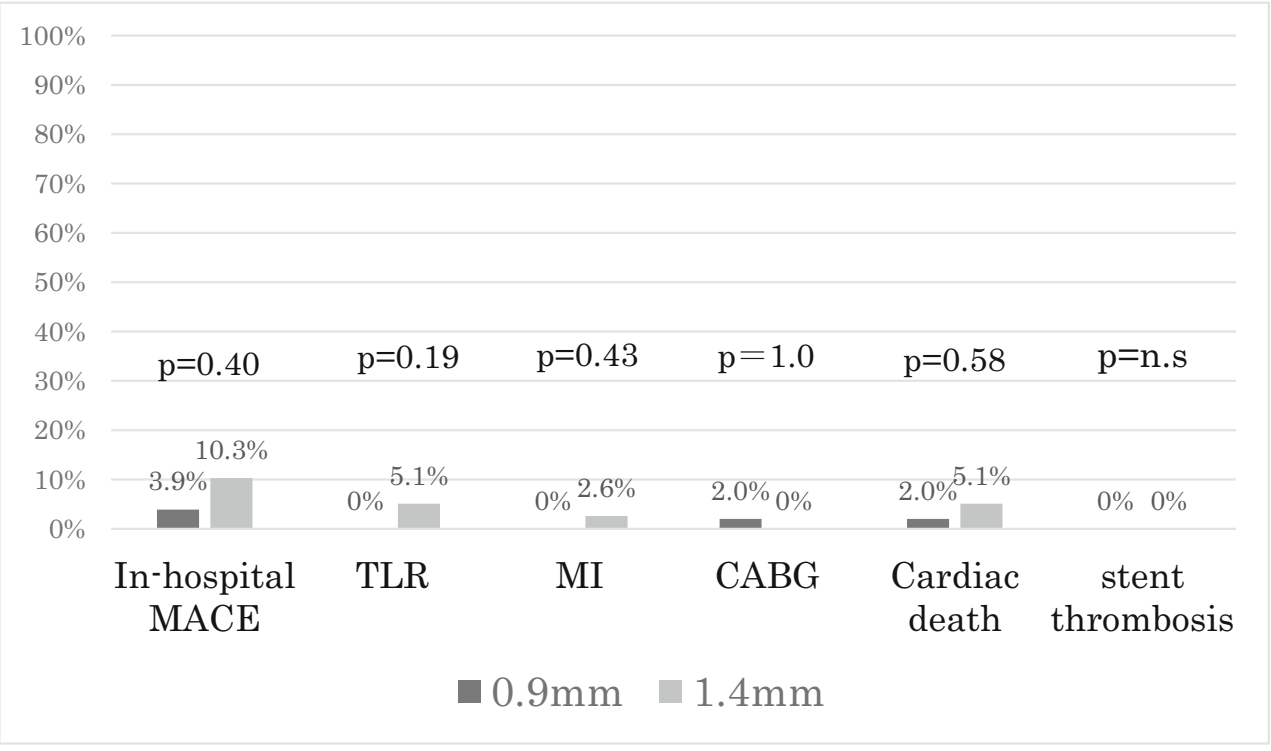

CABG, Coronary artery bypass grafting; MI, myocardial infarction; MACE, major adverse cardiac events; TLR, target lesion revascularization. a separate study showed that patient and lesion characteristics were not different between the AMI patients who received ELCA $(n=90)$ and those who did not $(n=50)$.

\section{Conclusion}

The efficacy of the 0.9-mm and 1.4-mm excimer laser catheter is equivalent in AMI patients. The 0.9-mm excimer laser catheter is likely a better choice going forward, although this will have to be confirmed by a prospective randomized study.

\section{Compliance with ethical standards}

Conflict of interest The authors declare that they have no conflict of interest.

Ethical approval This study was conducted in accordance with the principles of Declaration of Helsinki and in compliance with International Conference on Harmonization-Good Clinical Practice and local regulatory requirements. The study was performed with approval of the Tokyo Metropolitan Hiroo Hospital ethics committee. All of the patients provided written informed consent to receive ELCA treatment and have their data used.

Open Access This article is distributed under the terms of the Creative Commons Attribution 4.0 International License (http:// creativecommons.org/licenses/by/4.0/), which permits unrestricted use, distribution, and reproduction in any medium, provided you give appropriate credit to the original author(s) and the source, provide a link to the Creative Commons license, and indicate if changes were made.

\section{References}

1. Topaz O, Bernardo NL, Shah R, McQueen RH, Desai P, Janin Y et al (2001) Effectiveness of excimer laser coronary angioplasty in acute myocardial infarction or in unstable angina pectoris. Am J Cardiol 87:849-855

2. Ashikaga T, Yoshikawa S, Isobe M (2015) The efficacy of excimer laser pretreatment for calcified nodule in acute coronary syndrome. Cardiovasc Revasc Med 16:197-200

3. Topaz O, Shah R, Mohanty PK, McQueen RA, Janin Y, Bernardo NL (2001) Application of excimer laser angioplasty in acute myocardial infarction. Lasers Surg Med 29:185-192

4. Ilkay E, Karaca I, Yavuzkir M, Akbulut M, Pekdemir M (2005) The effect of interventional treatment in acute myocardial infarction on ST resolution: a comparison of coronary angioplasty with excimer laser angioplasty. Angiology. 56:377-384

5. Dorr M, Vogelgesang D, Hummel A, Staudt A, Robinson DM, Felix SB et al (2007) Excimer laser thrombus elimination for prevention of distal embolization and no-reflow in patients with acute ST elevation myocardial infarction: results from the randomized LaserAMI study. Int J Cardiol 116:20-26

6. Ambrosini V, Cioppa A, Salemme L, Tesorio T, Sorropago G, Popusoi G et al (2008) Excimer laser in acute myocardial infarction: single centre experience on 66 patients. Int J Cardiol 127:98-102

7. Ito H, Maruyama A, Iwakura K, Takiuchi S, Masuyama T, Hori M et al (1996) Clinical implication of the 'no reflow' phenomenon: a predictor of complication and left ventricular remodeling in reperfused anterior wall myocardial infarction. Circulation. 93:223-228

8. Morishima I, Sone T, Okumura K, Tsuboi H, Kondo J, Mukawa H et al (2000) Angiographic no-reflow phenomenon as a predictor of adverse long-term outcome in patients treated with percutaneous transluminal coronary angioplasty for first acute myocardial infarction. J Am Coll Cardiol 36:1202-1209

9. Topaz O, Eberesole D, Das T, Alderman EL, Madyoon H, Vora K et al (2004) CARMEL multicenter trial: excimer laser angioplasty 
in acute myocardial infarction (The CARMEL Multicenter Trial). Am J Cardiol 93:694-701

10. Shishikura D, Otsuji S, Takiuchi S, Fukumoto A, Asano K, Ikushima $\mathrm{M}$ et al (2013) Vaporizing thrombus with excimer laser before coronary stenting improves myocardial reperfusion in acute coronary syndrome. Circ J 77:1445-1452

11. O'Gara PT, Kushner FG, Ascheim DD, Casey DE Jr, Chung MK, de Lemos JA et al (2013) ACCF/AHA Task Force: 2013 ACCF/ AHA guideline for the management of ST-elevation myocardial infarction: executive summary: a report of the American College of Cardiology Foundation/American Heart Association Task Force on Practice Guidelines. Circulation. 127:529-555

12. Anderson JL, Adams CD, Antman EM, Bridges CR, Califf RM, Casey DE Jr et al (2013) American Heart Association Task Force on Practice Guidelines: 2012 ACCF/AHA focused update incorporated into ACCF/AHA 2007 guidelines for the management of patients with unstable angina/non-ST-elevation myocardial infarction: a report of the American College of Cardiology Foundation/ American Heart Association Task Force on Practice Guidelines. Circulation. 127:663-828

13. Topaz O, Lippincott R, Bellendir J, Taylor K, Reiser C (2001) "Optimally speed" excimer laser coronary catheters: performance analysis. J Clin Laser Med Surg 19:9-14

14. The Thrombolysis in Myocardial infarction (TIMI) trial (1985) Phase I findings: TIMI Study Group. N Engl J Med 312:932-936

15. van't Hof AW, Liem A, Suryapranata H, Hoorntie JC, de Boer MJ, Zijlstra F (1998) Angiographic assessment of myocardial reperfusion in patients treated with primary angioplasty for acute myocardial infarction: myocardial blush grade: Zwolle Myocardial infarction Study Group. Circulation. 97:2302-2306

16. Cutlip DE, Windecker S, Mehran R, Boam A, Cohen DJ, van Es GA et al (2007) Academic Research Consortium: clinical end points in coronary stent trials: a case for standardized definitions. Circulation. 115:2344-2351

17. Huber MS, Mooney JF, Madison J, Mooney MR (1991) Use of a morphologic classification to predict clinical outcome after dissection from coronary angioplasty. Am J Cardiol 68:467-471

18. Kloner RA, Ganote CE, Jennings RB (1974) The "no-reflow" phenomenon after temporary coronary occlusion in the dog. J Clin Investig 54:1496-1508

19. Nishino M, Mori N, Takiuchi S, Shishikura D, Doi N, Kataoka Tet al (2017) ULTRAMAN Registry investigators: indications and outcomes of excimer laser coronary atherectomy: efficacy and safety for thrombotic lesions-ULTRAMAN registry. J Cardiol 69:314-319

20. Rawins J, DIN JN, Talwar S, O'Kane P (2016) Coronary intervention with the excimer laser: review of the technology and outcome data. Interv Cardiol 11:27-32

21. Chen JF, Ahn SS (2011) Endovascular surgery (Fourth Edition)

22. Badr S, Ben-Dor I, Dvir D, Barbash IM, Kitabata H, Minha S et al (2013) The state of the excimer laser for coronary intervention in the drug-eluting stent era. Cardiovasc Revasc Med 14:93-98

23. Topaz O (1996) Plaque removal and thrombus dissolution with the photoacoustic energy of pulsed-wave lasers-biotissue interactions and their clinical manifestations. Cardiology. 87:384-391

24. Topaz O, Minisi AJ, Bernardo NL, Mc Pherson RA, Martin E, Carr SL et al (2001) Alterations of platelet aggregation kinetics with ultraviolet laser emission: the "stunned platelet" phenomenon. Thromb Haemost 86:1087-1093

Publisher's note Springer Nature remains neutral with regard to jurisdictional claims in published maps and institutional affiliations. 